\title{
PROJECTO EXEMPLAR NO ÂMBITO DA CULTURA LUSO-BRASILEIRA
}

José Cândido Oliveira Martins

(Universidade Católica Portuguesa)

\author{
SANTOS, Gilda (org.) 0 Real em Revista (Impressos luso- \\ brasileiros oitocentistas). \\ Rio de Janeiro: Oficina da Raquel, 2015
}

Organizado por Gilda Santos, a cuja capacidade de iniciativa, de liderança e de dinamismo a cultura luso-brasileira deve imenso, o volume $O$ Real em Revista (Impressos luso-brasileiros oitocentistas) é um eloquente output de um modelar projecto de pesquisa. Por informação dos textos iniciais - de A. Gomes da Costa, Presidente do RGPL e de Gilda Santos (p. 9-14), Coordenadora-geral do Projecto "O Real em Revista" -, o leitor fica a saber que os estudos coligidos neste volume foram previamente apresentados em mesas-redondas das "semanas de realizações" do Real Gabinete Português de Leitura (RGPL) do Rio de Janeiro; e que esta publicação se integra num conjunto bem maior de actividades, perfazendo um projecto de pesquisa verdadeiramente modelar. Entre outros resultados, destaque-se também a original colecção No Giro do Mundo, como forma de apresentação da hemeroteca do RGPL e divulgação dos primeiros resultados.

Mais concretamente, este é um dos resultados visíveis do notável projecto "O Real em Revista", vencedor do programa Petrobrás Cultural e, por isso, merecedor do alto patrocínio desta instituição. Este tipo de apoio financeiro dignifica a função social e mecenática de uma grande empresa como a Petrobrás e deveria constituir um exemplo a seguir por outras empresas, dotadas de uma filosofia social e cultural, indispensável ao cabal cumprimento da sua missão. Aliás, o rigoroso processo de selecção de que foi alvo o projecto de pesquisa do RGPL, no contexto de uma ampla concorrência com outros projectos, demonstra bem a qualidade da proposta de trabalho delineada por esta instituição, aliás na continuidade de outros importantes trabalhos de investigação, materializado na informatização da biblioteca, na realização de variados colóquios internacio- 
nais e da publicação de relevantes estudos (desde edições impressas até edições em suporte digital).

Com esse apoio determinante, pôde a equipa coordenada por Gilda Santos levar a cabo um importantíssimo trabalho de pesquisa, reunindo um apreciável conjunto de investigadores, sobretudo de universidades do Rio de Janeiro, desde pesquisadores séniores (já com inúmeras provas dadas), até jovens investigadores, numa relação fecunda e a vários títulos muito positiva. Além de outros investigadores convidados dos dois lados do Atlântico, que também mantêm interesses neste domínio de pesquisa.

Na prática, com esse indispensável apoio financeiro, uma variada equipa de investigadores pôde encetar - ao longo de um período relativamente curto (de janeiro de 2014 a agosto de 2015), mas suficiente - um trabalho pioneiro e da maior relevância: a digitalização de uma parte do importantíssimo acervo do RGPL, mais especificamente a partir de um ímpar corpus de publicações periódicas oitocentistas (jornais e revistas), de Portugal e do Brasil de Oitocentos. A uma instituição com a riqueza do acervo do RGPL - instituição fundada em 1837 - impende uma grande responsabilidade e, consequentemente, o dever ético de preservar e potenciar esse material único de pesquisa: primeiro, através da preservação de publicações raras; segundo, da sua disponibilização universal (em suporte eletrónico); terceiro, da produção de conhecimento correspondente.

A par desse trabalho de digitalização de seleccionadas colecções completas de periódicos (cerca de 35.000 páginas), privilegiando alguns domínios temáticos, e da sua consequente disponibilização no site do RGPL, promoveram-se variadas iniciativas, desde eventos científicos abertos, publicações diversas, serviço de visitas guiadas, elaboração de materiais pedagógicos, exposições, relação com outros centros de pesquisa, além de outras iniciativas não previstas no projecto inicial. Isto dá bem conta da diversidade do projecto em causa, mesmo que circunscrito a uma pequena parcela do referido acervo. Por outras palavras, estamos perante um caso absolutamente exemplar de como se deve preservar, potenciar e divulgar tão importante material de uma memória coletiva, quer para a comunidade internacional de investigadores, quer para o público em geral, que também deve conhecer esta realidade que faz parte da sua identidade histórica e cultural.

Na sequência do afirmado, o referido trabalho de digitalização permite reforçar a disponibilização de imprescindíveis materiais de pesquisa da hemeroteca do RGPL; e, ao mesmo tempo, propiciar novos elementos 
de informação ao nível da imprensa oitocentista para os mais diversos investigadores das áreas das ciências sociais e humanas, da História e da Sociologia à Cultura e à Literatura. Assim, a referida obra - O Real em Revista: impressos luso-brasileiros oitocentistas - apresenta-se como ilustrativo exemplo de pesquisa sobre tão relevante acervo. Sendo o ponto de chegada do citado projeto, é ao mesmo tempo um ponto de partida e um enorme desafio para inúmeros investigadores.

As duas dezenas e meia de textos deste volume são bem elucidativas da variedade potencial deste acervo e das suas fontes impressas, de que se disponibilizou recentemente mais uma parcela. Assim, na primeira secção ("Temas Luso-Brasileiros"), Eduardo da Cruz mostra-nos o ativo papel dos caixeiros nos periódicos do Grêmio Literário Português do Rio de Janeiro, por meados de Oitocentos, numa considerável variedade temática e de géneros. Imigrados de Portugal e de origem simples e provinciana, estes caixeiros literatos encontravam nessa forma de participação pública um modo de aprofundar autodidaticamente a sua instrução.

Já as comemorações do III Centenário da Morte de Camões em 1880 motivaram celebrações festivas, envolvendo instituições como o Gabinete Português de Leitura do Rio de Janeiro, como nos recorda Fabiano Cataldo de Azevedo. Contudo, a consulta de fontes mostra essa efeméride celebrativa do Poeta nos dois lados do Atlântico não foi consensual, tendo-se gerado polémicas sobre quem deveria ter protagonismo nessas celebrações camonianas em terras brasileiras, como espelhado em vários periódicos e na intervenção de variados intelectuais.

A investigadora Germana Maria Araújo Sales ocupa-se do relevante tema do trânsito de livros entre Portugal e o Brasil de Oitocentos, nomeadamente para a província do Grão-Pará. Afinal, o mercado de livros configurada uma das mais relevantes trocas culturais entre a Europa e diversos territórios brasileiros, como a cidade de Belém. Assim, a partir várias fontes de informação como os catálogos livreiros ou a frequência dias gabinetes de leitura ou grémios literários, é hoje possível saber que livros e autores eram mais procurados e lidos em determinado contexto social, investigação relevante para reconstituir as práticas de leitura de uma época.

É também possível rastrear nas fontes primárias da imprensa periódica de Oitocentos a diversidade da escrita de um autor como Machado de Assis, descortinando influências literárias, intelectuais e culturais. De facto, para além de outras relações, é possível diagnosticar 
"vínculos machadinhas com os portugueses" a vários níveis, como nos demonstra o investigador italiano Mauro Rosso. Mais uma vez, "a intensa e decisiva convivência de Machado com os literatos portugueses" aconteceu ao nível da imprensa periódica, isto é, jornais brasileiros onde aqueles colaboravam com mais ou menor assiduidade. E entre os "formadores do Machado escritor" contam-se nomes tão diversos como Camões, Garrett ou Camilo, entre outros.

Pelo afirmado, não surpreendem as considerações da investigadora Tania Maria Bessone T. da Cruz Ferreira, sobre as "relações luso-brasileiras nos periódicos do século XIX". Com efeito, os jornais foram palco privilegiado de confrontos políticos e ideológicos entre publicistas e intelectuais da época, pelo que a história das ideias e da cultura, bem como a história das relações entre os povos, não pode ignorar esse facto tão relevante. Afinal de contas, o texto impresso, com destaque para as publicações periódicas, assume várias funções, que confluem no papel de "edificar as nações".

Com enorme recepção pública, o popular Novo Almanaque de Lembranças Luso-Brasileiro é um excelente exemplo de publicação periódica que, dos dois lados do Atlântico, cumpria as tradicionais funções deste género de edição, com sua diversidade de temas e de colaboradores. Ora, na segunda metade de Oitocentos, entre os autores tratados, e demonstrando grande interesse pelo Brasil, destacam-se os escritores Gonçalves Dias e Álvares de Azevedo, que meterem aos editores do referido almanaque (como Rodrigues Cordeiro) a composição de curiosos perfis biográficoliterários, como nos informa Vania Pinheiro Chaves.

Já na segunda secção - "Temas Portugueses" - deparamo-nos com uma semelhante variedade temática. Abre com o estudo de Elza Assumpção Miné, incidindo sobre Jaime Batalha Reis e a sua colaboração na imprensa como crítico e cronista. A sua actividade consular, a partir de fora de Portugal, proporcionava-lhe um olhar crítico privilegiado, visível no considerável número de artigos que escreveu para vários jornais (incluindo a carioca Gazeta de Notícias) do final de Oitocentos e início do século seguinte, sobre diversas matérias, da arte à vida política e cultural, num memorialismo repleto de interesse.

Por sua vez, actualizando o trabalho de alguns investigadores com variadas informações, Ernesto Rodrigues debruça-se sobre o escritor Guilherme de Azevedo, poeta e dramaturgo português. Como nos aponta este investigador, é enorme a colaboração jornalística deste autor em diversas 
publicações periódicas. Desse laborioso e atento olhar é excelente exemplo o conjunto de crónicas quinzenais escritas para O Occidente: Revista Illustrada de Portugal e do Estrangeiro, em 1877, caracterizando o cronista o "estado de coisas nacional".

O Ultimato inglês de 11 de janeiro de 1890 desencadeou, consabidamente, um inflamado conjunto de reacções, cuja retórica anti-britânica se manifestou na pena e no registo de diversos autores. Isabel Pires de Lima analisa o caso exemplar da revista Anátema, da responsabilidade de estudantes de Coimbra, enquanto publicação periódica sintomática deste contexto conturbadíssimo da vida portuguesa. À sombra do genérico sentimento de finispatriae, confronta-se insistentemente um passado heroico a um presente de decadência, denunciando um Portugal decaído e humilhado.

Jorge Vaz de Carvalho debruça-se sobre Eça de Queirós e o seu romance Os Maias, centrando-se em dois tópicos - a problematizada questão do realismo em arte, tão debatida sempre e à qual o próprio Eça não fugiu, nomeadamente desde a célebre conferência do autor em 1871, por um lado; por outro, a recente adaptação cinematográfica do referido romance queirosiano, da autoria do realizador João Botelho.

$\mathrm{O}$ universo queirosiano também seduz a investigadora Monica Figueiredo que, num registo crítico e memorialístico, discorre sobre as razões da sedução exercida pela obra de Eça. Ilustrando com exemplos da escrita do autor de Os Maias, sustenta-se o argumento segundo o qual a "humana heroicidade" das criações queirosianas é a explicação chave de tal fascínio: "Inscritos na falha, os personagens queirosianos podem transpirar a mais pura humanidade, afastados que estão das prerrogativas da heroicidade".

António Pedro Lopes de Mendonça, escritor, folhetinista e crítico português, teve um papel activo na dinamização de $A$ Revolução de Setembro, em meados de Oitocentos. Escrevendo crónica-folhetim, crítica e breve narrativas, não escondeu as suas ideias sobre os rumos políticos da Regeneração. Isso mesmo se pode confirmar nas páginas em que se mostra um assertivo adversário das tendências absolutistas, desde os cabralistas aos regeneradores. A sua sensibilidade estética e carácter interventivo levam-no igualmente a pronunciar-se sobre a evolução literária, pelo que se justifica a reunião dos textos de Lopes de Mendonça nas páginas do referido periódico.

Na mais alongada terceira secção (“Temas Brasileiros”), enfatiza- 
-se a importância do conhecimento da imprensa oitocentista como fonte direta de informação sobre uma época. É o caso do estudo histórico de Ana Lucia Vieira dos Santos sobre a génese e representações da casa senhorial (seus proprietários, artistas e artífices) em publicações periódicas do terceiro quartel do séc. XIX, como o Almanak Laemmert, a Gazeta de Notícias ou o Jornal do Brasil.

Com preocupações históricas semelhantes, Angela Maria Cunha da Motta Telles investiga elementos para a história do café nas páginas da Revista Illustrada do último quartel de Oitocentos. Para isso destaca a atenção concedida às exposições da iniciativa do Centro da Lavoura e Commercio, dentro e fora do Brasil, com realce para as figuras de Eduardo de Lemos e Joaquim Ramalho Ortigão. Também aqui o importante acervo documental à guarda do RGPL se revela uma fonte de informação imprescindível.

Igualmente Carlos Kessel se serve da documentação do RGPL, nomeadamente a sua inestimável colecção de periódicos (revistas brasileiras ilustradas do final de Oitocentos), para aprofundar os tesouros do Morro do Castelo, num trabalho que já vem de outras pesquisas anteriores. Também para Iza Terezinha Gonçalves Quelhasos periódicos pós-independência (como o jornal A Aurora Fluminense, editado a partir de 1827) se revelam uma fonte ímpar de informação. Publicações como a mencionada tiveram um papel importante na formação identitária, de uma "comunidade estética e política",por intermédio da escrita, papel materializado na formação de uma opinião pública e de um público leitor.

Na senda da enorme popularidade do género do romance-folhetim, de matriz francesa, mas com reconhecida popularidade no Brasil, e próximo do modelo de Eugène Sue (de Os Mistérios de Paris), Jacqueline Penjon apresenta-nos exemplos paradigmáticos da "mysterymania" que assolou a época. A saber, a partir de meados de Oitocentos, também no Brasil se editaram obras dentro da mesma filosofia compositiva e com os mesmos ingredientes do género - Os mysterios do Rio de Janeiro e os legítimos desherdados; Os mysterios do Rio de Janeiro ou os ladrões de casaca; etc. - primeiro sob a forma de folhetim jornalístico, depois no formato de livro.

A par dos estudos do citado Mauro Rosso, de novo Machado de Assis e as suas crónicas editadas em alguns periódicos - é o tema do estudo de Kenneth David Jackson. Entre os anos de 1859 e 1900, por cerca de quatro décadas, o escritor publica em periódicos diversos, desde 
O Parahyba ou Correio Mercantil, até à Gazeta de Notícias, tornando-se reconhecido mestre do género. De temática muito variada, a escrita cronística machadiana distingue-se sobretudo pela inventividade e estilo aforismático, pela crítica e humor.

A moradia urbana e os ambientes domésticos da segunda metade do séc. XIX são objecto de análise de Luciano Caetano. Afinal de contas, as mudanças a este nível (interiores das habitações, tipos de decoração, estilos dominantes, etc.) são muito reveladoras da evolução social - "Dize-me como moras e eu te direi quem és", afirmara Machado de Assis. Um exemplo paradigmático é constituído pelas diversas casas de Rui Barbosa, de que o investigador traça uma sugestiva panorâmica.

Totalizando cerca de duas centenas, os contos de Machado de Assis na imprensa brasileira motivam um estudo de Marta de Senna, também responsável por uma edição online, de natureza hipertextual, dos textos machadianos em Contos em hipertexto (www.machadodeassis.net). Essa assídua colaboração, às vezes sob pseudónimo, era uma prática de muitos escritores e intelectuais de Oitocentos. Quando confrontada com as edições em livro e em circulação, a fixação dos machadianos "contos de jornal" levanta problemas de vária ordem: erros de transcrição, gralhas diversas, problemas de hipercorreção, dificuldades das alusões histórico-culturais, bem como de citações e referências intertextuais.

A imprensa periódica constitui também uma fonte documental privilegiada para quem pretende conhecer a História do Teatro como História do Espetáculo, como estudado por Tania Brandão. Na sua variedade tipológica, os textos publicados na imprensa sobre o teatro mostram-se muito relevantes, mesmo que sujeitos a uma necessária crítica das fontes. Ora, é justamente neste contexto que sobressai, uma vez mais, a riqueza do acervo do RGPL, nomeadamente ao nível de jornais e revistas de Oitocentos, fornecendo preciosas informações sobre os mais diversos aspectos do espetáculo teatral, desde a encenação à recepção crítica.

Por fim, o volume que temos vindo a apresentar contempla ainda uma derradeira secção - "Revisita aos Gabinetes de Leitura" -, constituída por quatro textos breves: Rita Aparecida Coelho Santos aborda o Real Gabinete de Leitura de Salvador, partindo da história da sua fundação (1863) para os variados desafios que enfrenta no presente (em 2012, na celebração dos 150 anos de existência), a justificar urgentes estratégias de revitalização como espaço de memória e de cultura. Também Francisco Ferreira Lima discorre sobre o Gabinete Português de Leitura da Bahia, 
quer do ponto de vista histórico, também se detendo na absoluta necessidade da sua revitalização como casa de cultura, em articulação com outras instituições (desde as universidades da região à recém-fundada Cátedra Fidelino de Figueiredo), sempre em prol da cultura contemporânea. Por fim, José Rodrigues de Paiva apresenta o Gabinete Português de Pernambuco (Recife), desde o seu passado às perspectivas de futuro. A encerrar a secção, um conto de Lucila Nogueira, "ambientado no Gabinete Português de Leitura do Recife".

Concluamos rapidamente: em qualquer país desenvolvido, a política cultural e de investigação científica faz-se com projectos concretos - e não com discursos mais ou menos retóricos e com boas intenções -, projectos devidamente planeados e apoiados, dinamizados por equipas competentes e empenhadas, potenciando sinergias de diversas instituições, e visando o avanço do conhecimento. Esse é (foi) o caso exemplar do projecto "O Real em Revista", agregando vários investigadores em torno de um plano de trabalho muito pertinente, concretizado num articulado conjunto de actividades. Reunidas estas condições, está garantido o sucesso.

\section{REFERÊNCIAS}

CRUZ, Eduardo da (org.). No Giro do Mundo. Vol. I. Rio de Janeiro: Real Gabinete de Leitura, 2014.

CRUZ, Eduardo da; FERREIRA, Tania Maria Bessone da Cruz (org.). No Giro do Mundo. Vol. II. Rio de Janeiro: Real Gabinete de Leitura, 2015.

CRUZ, Eduardo da (org.). No Giro do Mundo. Vol. III. Rio de Janeiro: Real Gabinete de Leitura, 2015.

"O Real em Revista" - projecto de pesquisa, disponível em: $<$ http://www.orealemrevista.com.br/>. Acesso em: 25 julho 2016.

SANTOS, Gilda (org.). O Real em Revista (Impressos luso-brasileiros oitocentistas). Rio de Janeiro: Oficina da Raquel, 2015.

Recebido em: 05 de agosto de 2016

Aceito em: 19 de outubro de 2016 